\title{
Impact of COVID-19 Lockdown on Depression Severity and the Use of Drugs Among University of Ibadan Students
}

Abdulhammed Opeyemi Babatunde, ${ }^{1,2^{*}}$ Dimeji AbdulSobur Olawuyi, ${ }^{1}$ Habib Ayomide Shobanke, ${ }^{1}$ Adeniyi Abraham Adesola, ${ }^{1}$ Christabel ljeoma UcheOrji, ${ }^{1}$ Boluwatife Adefunke Bolatito, ${ }^{1}$ Yeshua Ayokun Adedeji,' AbdulSobur Olatunde Abdulazeez,' Lordstrong Akano Olaniyi,' Dolapo Michael Babalola.

\begin{abstract}
Background: Since the declaration of COVID-19 as a pandemic, measures such as nationwide lockdowns have been implemented. The sudden disruption of activities coupled with fear could trigger or aggravate mental illnesses and consequently, increase substance use as a coping mechanism. This study then sought to assess the impact of the lockdown on depression and substance use amongst students in a tertiary institution in Ibadan city, Nigeria. Methods: A self-administered 26 questions online questionnaire was employed for data collection of socio-demographic characteristics, Patient Health Questionnaire (PHQ-9) to assess depression, and a section on the use of psychoactive drugs during lockdown. Data were statistically analyzed using IBM's SPSS and Microsoft Excel. Results: We gathered 102 responses, 54.9\% were males. Most of the respondents had mild depression (41.2\%), followed by $36.3 \%$ that reported not having an episode of depression, $15.7 \%$ moderate, $4.9 \%$ moderately severe, and $2 \%$ severe depression. Female had more depressive episodes than males $(p=0.185)$. Only $4 \%$ reported substance use since the pandemic, all were male. At a $95 \%$ confidence interval, there was no significant association between the level of depression and any socio-demographic characteristics of students and between the level of depression and drug use. Conclusions: According to this study, lockdown and other mitigation strategies implemented during the pandemic were not found to be associated with drug use. A limitation of this study is the cross-sectional design, as a result, a larger multicenter study is needed to ascertain the possible association between lockdown, depressive symptoms, and drug use among students.
\end{abstract}

Key Words: Depression; COVID-19; Drug Abuse; Mental Health; PHQ-9; Medical students (Source: MeSH-NLM).

\section{Introduction}

Coronaviruses are a group of enveloped viruses with a single-stranded, positive-sense RNA genome known to cause respiratory infections such as Middle East Respiratory Syndrome (MERS) and Severe Acute Respiratory Syndrome (SARS). ${ }^{1}$ In December 2019 , a novel coronavirus, SARS-CoV-2 which was first identified as a viral pneumonia of unknown origin was first confirmed in Wuhan, China.' Some symptoms of the coronavirus infection include: fever, chills, cough, sore throat, myalgia, nausea, and diarrhea. ${ }^{2}$ In January 2020, the World Health Organization (WHO) declared the disease to be an emergency internationally, with regards to public health and thereafter named it a pandemic on 11th March, 2020.3,4 Therefore, in order to effectively combat this pandemic, governments of countries around the world imposed a compulsory lockdown and cessation of economic activities. These policies have affected the social experience of the populace especially university students with respect to their mental well-being. ${ }^{5}$

A major adverse effect of the COVID-19 pandemic is increased social isolation which is strongly affiliated with anxiety, depression, and drug use. ${ }^{6}$ Stringent measures such as lockdown of all schools, restricted movement among other measures, have disrupted daily living for most university students. ${ }^{7}$ Early evidence from published studies suggests that COVID-19 is associated with the prevalence of mental and psychological illnesses like depression, anxiety, and post-traumatic stress disorder.? Due to this association, the COVID-19 pandemic can be considered a traumatic event.
According to WHO reports, community-based studies revealed an overall prevalence of mental disorders around $25 \%$ in several national or cultural contexts. ${ }^{8}$ Besides, the abuse of common drugs such as hallucinogens (drugs that affect thought, feeling), nicotine, opioids (drugs that relieve pain), and sedatives have also increased significantly. ${ }^{9}$ Depression, having seen to be one of the consequences of substance abuse, is also recognized as a form of mental illness. ${ }^{10}$ Recently, studies regarding mental health in relation to the outbreak, were conducted in Asia and focused on specific sub-populations such as college students and medical workers and indicated that the majority of the participants $(63.5 \%)$ exhibited depressive symptoms in varying degrees. ${ }^{5}$ Self-reported depression, anxiety, and suicidal attempts were found to be associated with COVID-19 related issues such as self-isolation, quarantine, misinformation, deaths, and others among health workers and the general public. ${ }^{11}$ Besides, the effect of COVID19 pandemic on benzodiazepine and alcohol abuse - there was an increase in their abuse in some areas while lockdown caused a shortage and reduced access to benzodiazepine and alcohol in some other areas. ${ }^{12,13}$

To the best of our knowledge, there has not been any study to evaluate the relationship between depression and substance use by students due to the COVID-19 lockdown in sub-Saharan Africa. Hence, this study seeks to examine how this pandemic has caused depression and possibly drug abuse among the students at the University of Ibadan. It also aims to test for the relationship between demographic characteristics of students and severity of depression.

11 Department of Medicine and Surgery, Faculty of Clinical Sciences, College of Medicine, University of Ibadan, Ibadan, Nigeria

2 Healthy Africans Platform, Ibadan, Nigeria

About the Author: Abdulhammed Opeyemi Babatunde is currently a 4th year medical student of College of Medicine, University of Ibadan, Ibadan, Nigeria of a 6-year program. He is also the local officer, Federation of African Medical Students' Associations Standing Committee on Medical Education and Research.

Correspondence:

Abdulhammed Opeyemi Babatunde

Address: Queen Elizabeth I I Road, Agodi 200285, Ibadan, Nigeria Email: abdulhammedbabatunde99@gmail.com
Editor: Sohaib Haseeb Student Editors: Leah Komer, Samreen Fathima, Brandon Belbeck o Johnmark Boachie Copyeditor: Benjamin Liu Proofreader: Madeleine Jemima Cox Layout Editor: Judie 100
Submission: Nov 9, 2020 Revisions required: Jan 18, Mar 9. Apr 28, Aug 252021 Received in revised form: Jan 26, Mar 14, Apr 29, Sep 9, 2021 Acceptance: Sep 29, 2021 Publication: Sep 29, 2021 Process: Peer-reviewed 


\begin{abstract}
Methods
Study design

The study was a cross-sectional study carried out among the students at the University of Ibadan, Nigeria during the COVID-19 pandemic. Data were collected from July to August 2020.
\end{abstract}

\section{Population and Sample}

The study population comprised of the current undergraduate students at the University of Ibadan with access to smartphones and the internet. About 30,000 students are currently enrolled in the university. All participants were provided with a consent form to either decline or accept to take part in the study. All respondents consented willingly to taking part in the survey. The link to the survey was randomly sent to students at the University through WhatsApp groups for different departments and halls of residence. Also, each co-author shared the link privately with up to 50 contacts eligible for the study.

\section{Data collection instruments}

The online questionnaire administered was composed of 26 questions which were divided into three sections which include: sociodemographic characteristics, assessment of depression, and assessment of drug use. Sociodemographic characteristics included data on age range, religion, gender, faculty, and year of study.

The severity of depressive symptoms of the students was assessed through the questionnaire tool, Patient Health Questionnaire (PHQ-9) in English. The PHQ-9 is a self-administered version of the PRIME-MD diagnostic instrument for common mental disorders. ${ }^{14}$ The PHQ-9 is the depression module, which scores each of the 9 DSM-IV criteria as ' 0 ' (not at all), ' 1 ' (several days), ' 2 ' (more than half the days), and ' 3 ' (nearly every day). It has been validated for use in primary care. ${ }^{15}$ The results had been recorded into five severity categories: 0-4 as 'none', 5-9 as 'mild', 10-14 as 'moderate', 15-19 as 'moderately severe', 20-27 as 'severe'. ${ }^{11}$ The respondents were asked six questions to assess their drug use during the pandemic.

A pilot survey was initially conducted to test the feasibility and efficiency of the questionnaire and data collected was not included in the study.

\section{Data analysis}

The data gathered was saved as Google Sheet then exported to Microsoft Excel package for cleaning and scoring. Descriptive analysis with pie and bar charts was also conducted on Microsoft Excel. Proper tabulation and statistical analysis for Chi-Square test were performed using the Statistical Packages for Social Sciences (SPSS) version 19. A Chi-square test was conducted using SPSS to determine the relationship between depression and socio-demographic characteristics with Pvalue which indicates whether the relationship is statistically significant. A P-value of, 0.05 at $95 \%$ confidence interval was statistically significant.

\section{Results}

\section{Sociodemographic}

In terms of gender, $56(54.9 \%)$ were males while $46(45.1 \%)$ were females. Most of the participants are young adults within the age group of 19-21 years old (55.9\%). Religious backgrounds included Christians (79\%), Muslims (20\%), and African traditional religion (1.0\%). Most of the students were in the 2nd year (35.3\%) and 3 rd year (34.3\%). $51 \%$ of participants were in the Faculty of Clinical Sciences while the remaining were spread across 11 other faculties. Table 1 shows the socio-demographic characteristics of participants.

\section{Depression Severity}

The level of depression severity found, using the PHQ-9 questionnaire is shown in Figure 1. The comparison of depression severities between male and female students is shown in Figure $2(p$-value $=0.185) .44 .6 \%$
Table 1. Descriptive Analysis for Socio-Demographic Statistics.

\begin{tabular}{|c|c|}
\hline Study variables & $\begin{array}{c}n(\%) \\
{[n=102]}\end{array}$ \\
\hline \multicolumn{2}{|l|}{ Gender } \\
\hline Male & $56(54.9)$ \\
\hline Female & $46(45.1)$ \\
\hline \multicolumn{2}{|l|}{ Age } \\
\hline $16-18$ & $19(18.6)$ \\
\hline $19-21$ & $57(55.9)$ \\
\hline $22-25$ & $21(20.6)$ \\
\hline 25 and above & $5(4.9)$ \\
\hline \multicolumn{2}{|l|}{ Religion } \\
\hline African traditional religion & 1(1) \\
\hline Christianity & $81(79.4)$ \\
\hline Islam & $20(19.6)$ \\
\hline \multicolumn{2}{|l|}{ Faculty } \\
\hline Agriculture and forestry & $8(7.8)$ \\
\hline Arts & $3(2.9)$ \\
\hline Basic medical sciences & $9(8.8)$ \\
\hline Clinical sciences & $52(51)$ \\
\hline Dentistry & $7(6.9)$ \\
\hline Economic and management science & $2(2)$ \\
\hline Education & $2(2)$ \\
\hline Law & $2(2)$ \\
\hline Pharmacy & $1(1)$ \\
\hline Sciences & $6(5.9)$ \\
\hline Technology & $6(5.9)$ \\
\hline The social sciences & $4(3.9)$ \\
\hline \multicolumn{2}{|l|}{ Year of study } \\
\hline 1st & $8(7.8)$ \\
\hline 2nd & $36(35.3)$ \\
\hline 3 rd & $35(34.3)$ \\
\hline 4th & $17(16.7)$ \\
\hline 5th & 4(3.9) \\
\hline 6th & $2(2)$ \\
\hline
\end{tabular}

Figure 1. Level of depression among university students

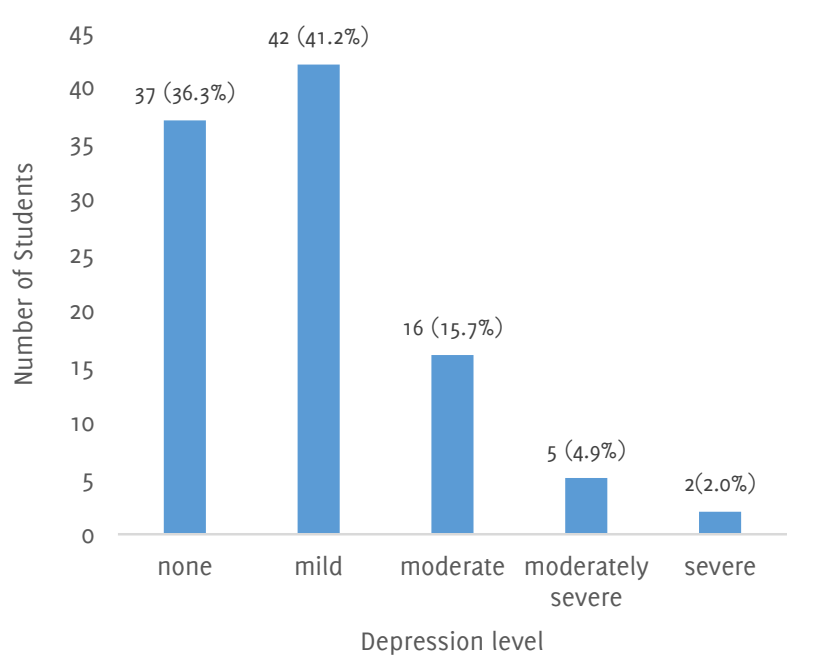

of males and $26.0 \%$ of females showed no level of depression. There was no significant association between the level of depression and any socio-demographic characteristics of students (Table 2).

\section{Drug Use}

Only 4 (4\%) participants responded to have started taking psychoactive drugs only when COVID-19 started, and they were all males. Opioids (tramadol), tobacco, and marijuana were the psychoactive substances used. The drugs were taken for relaxation, sleep stimulants, and boredom. There was no significant association between the level of depression and drug use among the students $(P$-value $=0.650$. 
Table 2. Relationship between Depression and Socio-Demographic Characteristics

\begin{tabular}{|c|c|c|c|c|c|c|}
\hline Characteristics & $\begin{array}{c}\text { None }[\mathrm{n}=37] \mathrm{n} \\
(\%)\end{array}$ & $\begin{array}{c}\text { Mild } \\
{[n=42] n(\%)}\end{array}$ & $\begin{array}{c}\text { Moderate } \\
{[n=16] n(\%)}\end{array}$ & $\begin{array}{c}\text { Moderately severe } \\
{[n=5] n(\%)}\end{array}$ & $\begin{array}{c}\text { Severe } \\
{[n=2] n(\%)}\end{array}$ & $P$-value \\
\hline \multicolumn{7}{|l|}{ Age group } \\
\hline $16-18$ & $7(18.9)$ & $6(14.3)$ & $4(25)$ & $1(20.0)$ & $1(50.0)$ & 0.704 \\
\hline $19-21$ & $19(51.4)$ & $24(57.1)$ & $9(56.2)$ & $4(80.0)$ & $1(50.0)$ & \\
\hline $22-24$ & $7(18.9)$ & $11(26.2)$ & $3(18.8)$ & $0(0.0)$ & $0(0.0)$ & \\
\hline 25 and above & $4(10.8)$ & $1(2.4)$ & $0(0.0)$ & $0(0.0)$ & $0(0.0)$ & \\
\hline \multicolumn{7}{|l|}{ Gender } \\
\hline Male & $25(67.6)$ & $22(52.4)$ & $7(43.8)$ & $2(40.0)$ & $0(0.0)$ & 0.185 \\
\hline Female & $12(32.4)$ & $20(47.6)$ & $9(56.2)$ & $3(60.0)$ & $2(100.0)$ & \\
\hline \multicolumn{7}{|l|}{ Religion } \\
\hline Christianity & $31(83.8)$ & $35(83.3)$ & $11(68.8)$ & $2(40.0)$ & $2(100.0)$ & 0.310 \\
\hline Islam & $6(16.2)$ & $6(14.3)$ & $5(31.2)$ & $3(60.0)$ & $0(0.0)$ & \\
\hline African Tradition & & $1(2.4)$ & $0(0.0)$ & $0(0.0)$ & $0(0.0)$ & \\
\hline \multicolumn{7}{|l|}{ Year of study } \\
\hline 1St & $2(5.4)$ & $3(7.1)$ & $2(12.5)$ & $1(20.0)$ & $0(0.0)$ & 0.813 \\
\hline 2nd & $14(67.8)$ & $12(28.6)$ & $7(43.8)$ & $1(20.0)$ & $2(100.0)$ & \\
\hline $3 r d$ & $14(37.8)$ & $14(33.3)$ & $4(25.0)$ & $3(60.0)$ & $0(0.0)$ & \\
\hline 4 th & $5(13.5)$ & $10(23.8)$ & $2(12.5)$ & $0(0.0)$ & $0(0.0)$ & \\
\hline 5th & $2(5.4)$ & $1(2.4)$ & $1(6.2)$ & $0(0.0)$ & $0(0.0)$ & \\
\hline 6th & $0(0.0)$ & $2(4.8)$ & $0(0.0)$ & $0(0.0)$ & $0(0.0)$ & \\
\hline
\end{tabular}

Figure 2. Comparison between Level of Depression and Cender

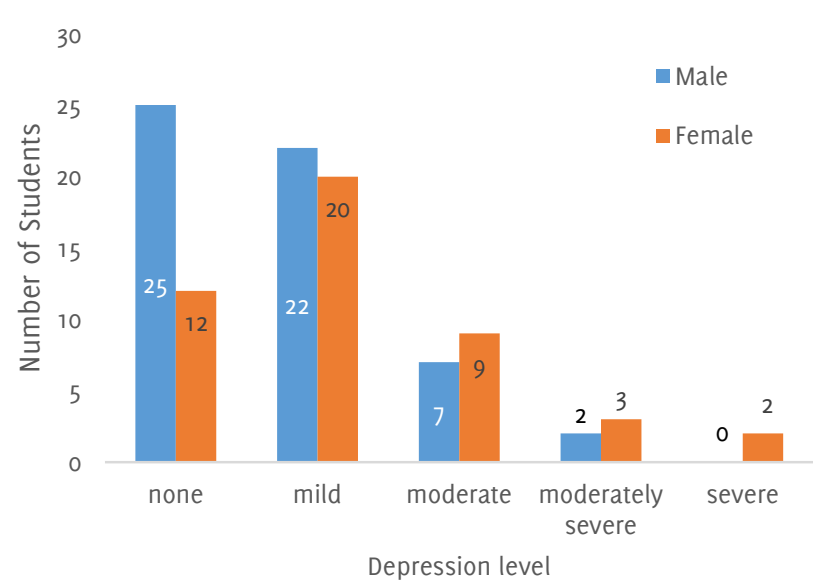

\section{Discussion}

Overall, University of Ibadan students reported depressive symptoms with a larger portion reporting mild and moderately severe depressive symptoms which may be due to several indoor coping strategies. This is consistent with the study done in Bangladesh. ${ }^{16}$ The same is the case with the use of psychoactive drugs; $4.0 \%$ of participants recorded that they started using psychoactive drugs such as opioids (tramadol), tobacco, and marijuana during the COVID-19 lockdown. The drugs were taken for relaxation, sleep stimulation, and boredom. Studies have shown that both loneliness and social isolation are associated with decreased cognitive function. ${ }^{17}$ There is a possibility that home confinement during the COVID-19 pandemic increased daytime stress, anxiety level, and depression level because most people, including students, are living with changes in their routine, uncertainty about their health, and they cannot participate in vitality giving activities like sport, visiting, friends, and going to religious gatherings. ${ }^{18-20}$

Although not statistically significant, depressive symptoms were higher in female students compared to male students as more females reported moderate, moderately severe, and severe depressive symptoms than male students. This finding correlates with a recent study done in a cohort in Cyprus which showed that women were more likely to have depressive symptoms than men. ${ }^{21}$ Depressive symptoms were most prevalent among the 19-21 age groups. One possible explanation for this is that the lower age groups can still afford to be under the protection of their parents or guardians that ensure better decisions on their mental health while those in the 19-21 age group are old enough to make their own decisions about their mental space albeit poorly. ${ }^{21}$ A study in Trinidad showed that University students with good religious practices, and who regarded their faith as important, are less likely to have depressive symptoms. ${ }^{22,23}$ Unfortunately, due to lockdown the campus religious activities were discontinued which might have contributed to depressive symptoms in some students.

Fear, stress, anxiety, and, in worse case scenarios, depression are all side effects of the lockdown. ${ }^{24}$ People living with physical and/or mental health conditions have been found to be more vulnerable to these effects of the lockdown. ${ }^{24}$ University students generally comprise a population that experience a high level of psychological distress. Anxiety levels and depression are likely to increase during the lockdown characterized by social distance, isolation, and quarantine. Seeing that their daily routines and activities are disrupted, boredom and sleep problems would not be far-fetched. Increased alcohol consumption, smoking, and abuse of psychoactive substances are likely side effects of the lockdown on this population. ${ }^{25}$

Medications, binge-watching TV series, surfing the internet, watching pornography, and few other things have been suggested to relieve stress and shun difficult thoughts. ${ }^{26-29}$ Use of these substances as well as engaging in the activities are some of the possible social behaviors to alleviate mental stress of the lockdown and pandemic. Nevertheless, there remains a high tendency that they may advance into habits which are quite difficult to break. ${ }^{30-31}$

Alcohol and other psychoactive drugs interfere with the nervous system and they are ingested at alarming rates by people avoiding difficult thoughts, unpleasant emotions, anxiety, and stress.33-35 It was suggested that alcohol is the most used psychoactive substance after caffeine; followed by smoking tobacco and lastly recreational drugs. ${ }^{36}$ 
Psychoactive substances like opioids (e.g. tramadol), tobacco, and marijuana were found to be consumed by the participants. Although the level of depression and drug use among students did not have an association that is statistically significant (P-value $>0.05$ ), $4 \%$ of the participants started taking psychoactive substances during the lockdown.

Besides, although the mental health of the entire populace might be affected by the pandemic, the marginalized populations may have a higher risk due to a larger number of daily stressors and an even larger strain on resources. ${ }^{37}$

\section{Limitations}

There were some limitations and challenges encountered in the study which included the method of data collection, that is, online data collection which was employed primarily due to lockdown. Only eligible participants with access to a mobile phone or the internet could participate, potentially affecting the generalizability of the results. Also, there is a risk of selection and information bias due to the online data collection method. Besides, the low reported number of drug use may

\section{References}

1. Wang Y, Grunewald M, Perlman S. Coronaviruses: An Updated Overview of Their Replication and Pathogenesis. Methods Mol Biol. 2020;2203:1-29.

2. Salari N, Hosseinian-Far A, Jalali R, Vaisi-Raygani A, Rasoulpoor S, Mohammadi $M$, et al. Prevalence of stress, anxiety, depression among the general population during the COVID-19 pandemic: a systematic review and meta-analysis. Global Health. 2020 Jul 6;16(1):57.

3. World Health Organization. Regional Office for Europe. WHO announces COVID-19 outbreak a pandemic. Available from: https://www.euro.who.int/en/healthtopics/health-emergencies/coronavirus-covid-19/news/news/2020/3/whoannounces-covid-19-outbreak-a-pandemic. Last updated Mar 12, 2020; cited Sep 9, 2020.

4. Zhang Y, Ma ZF. Impact of COVID-19 pandemic on mental health and quality of life among local residents in Liaoning Province China: a cross sectional study. Int J Environ Res Public Health. 2020 Mar 31;17(7):2381.

5. Mazza C, Ricci E, Biondi S, Colasanti M, Ferracuti S, Napoli C, et al. A Nationwide Survey of Psychological Distress among Italian People during the COVID-19 Pandemic: Immediate Psychological Responses and Associated Factors. Int J Environ Res Public Health. 2020 May 2;17(9):3165.

6. Holmes EA, O'Connor RC, Perry VH Tracey I, Wessely S, Arseneault L, et al. Multidisciplinary research priorities for the COVID-19 pandemic: a call for action for mental health science. Lancet Psychiatry. 2020 Jun;7(6): 547-60.

7. Ethman CK, Abdalla SM, Cohen CH, Sampson L, Vivier PM, Galea S. Prevalence of depression symptoms in US adults before and during the COVID-19 pandemic. JAMA Netw Open. 2020 Sep 1;3(9):e2019686

8. Alharbi R, Alsuhaibani K, Almarshad A, Alyahya A. Depression and anxiety among high school students at Qassim region. J Family Prim Care. 2019 Feb;8(2):504-10.

9. Gulf Bend Center. Substance/Medication-Induced Depressive disorder. Available from: https://www.gulfbend.org/poc/view_doc.php?type=docctid=12981 $\mathrm{cten}=$. Last updated 2008; cited Sep 20, 2020.

10. Smith K. PSYCOM. Substance abuse and Depression. Available from: https://www.psycom.net/depression-substance-abuse. Last updated November 2018; cited Sept 20, 2020.

11. Wright K, Sarangi A, Ibrahim Y. The psychiatric effects of COVID-19 thus far: a review of the current literature. The Chronicles. 2020Jul.23;8(35):17-8.

12. Sarangi A, Mcmahon T, Gude J. Benzodiazepine Misuse: An Epidemic Within a Pandemic. Cureus. 2021;13(6): e15816.

13. Sarangi A, Eskander N. The Worsening Outcomes of the COVID-19 Lockdowns on Patients with a History of Alcoholism, Alcoholism Treatment Quarterly. 2021;39:3, 342-347

be because respondents already started taking psychoactive substances before the lockdown. Also, the study was conducted only in one University, hence, the external validity is limited, and the result may not apply to the general population because of the small sample size. Lastly, we could not ascertain background psychiatric conditions in participants.

\section{Conclusion}

The level of depression among the study participants was high and not associated with gender. However, the severity was minimal. Government and stakeholders should consider the impact of lockdown and other mitigating strategies for reducing the transmission of COVID19 and future public health emergencies on the mental health of youths and the general population while making policies. A multicentered study would be necessary to assess the incidence as well as the severity of depression on a larger scale. We also suggest that this study should be replicated among the marginalized populations.

15. Cameron IM, Crawford IR, Lawton K, Reid IC. Psychometric comparison of PHQ-9 and HADS for measuring depression severity in primary care. Br ] Gen Pract. 2008 Jan;58(546):32-6.

16. Islam MA, Barna SD, Raihan H, Khan MNA, Hossain MT. Depression and anxiety among university students during the COVID-19 pandemic in Bangladesh: A webbased cross-sectional survey. PLoS One. 2020 Aug 26;15(8):e0238162.

17. Lara E, Caballero FF, Rico-Uribe LA, Olaya B, Haro JM, Ayuso-Mateos JL, et al. Are Ioneliness and social isolation associated with cognitive decline? Int J Geriatr Psychiatry. 2019 Nov;34(11):1613-22.

18. Altena E, Baglioni C, Espie CA, Ellis J, Gavriloff D, Holzinger B, et al. Dealing with sleep problems during home confinement due to the COVID-19 outbreak: Practical recommendations from a task force of the European CBT-I Academy. J Sleep Res. 2020 Aug;29(4):e13052.

19. Li $Y$, Qin $Q$, Sun $Q$, Vgontzas AN, Tang $X$. Insomnia and psychological reactions during the COVID-19 outbreak in China. J. Clin. Sleep Med. 2020 Aug 15;16(8):1417-18

20. Huang Y, Zhao N. Generalized anxiety disorder, depressive symptoms and sleep quality during COVID-19 outbreak in China: a web-based cross-sectional survey. Psychiatry Res. 2020 Jun;288:112954.

21. Solomou I, Constantinidou F. Prevalence and Predictors of Anxiety and Depression Symptoms during the COVID-19 Pandemic and Compliance with Precautionary Measures: Age and Sex Matter. Int. J. Environ. Res. Public Health. 2020 Jul 8;17(14):4924.

22. McCullough ME, Larson DB. Religion and depression: a review of the literature. Twin Res. 1999 Jun;2(2):126-36.

23. Vasegh S, Mohammadi MR. Religiosity, anxiety, and depression among a sample of iranian medical students. Int. J. Psychiatry Med. 2007 Jan;37(2):213-27.

24. Gureje 0, Lasebikan V0, Ephraim-Oluwanuga 0, et al. Community study of knowledge of and attitude to mental illness in Nigeria. Br J Psychiatry. 2005 May; 186:436-41.

25. Meo SA, Abukhalaf AA, Alomar AA, Sattar K, Klonoff DC. COVID-19 Pandemic Impact of Quarantine on Medical Students' Mental Wellbeing and Learning Behaviors. Pak J Med Sci. 2020 May;36(COVID19-S4):S43-S48.

26. Blasi MD, Giardina A, Giordano C, Coco CL, Tosto C, Billieux J, et al. Problematic video game use as an emotional coping strategy: Evidence from a sample of MMORPG gamers. J Behav Addict. 2019 Mar 1;8(1):25-34.

27. Jacobs DF. A general theory of addictions: A new theoretical model. J Gambling Stud. 1986 Mar;2:15-31. 
28. Khantzian EJ. Addiction as a self-regulation disorder and the role of selfmedication. Addiction. 2013 Apr;108(4):668-9.

29. Király 0, Urbán R, Griffiths MD, Ágoston C, Nagygyörgy K, Kökönyei G, et al. The mediating effect of gaming motivation between psychiatric symptoms and problematic online gaming: an online survey. J Med Internet Res. 2015 Apr 7;17(4):e88.

30. King DL, Delfabbro PH, Billieux J, Potenza MN. Problematic online gaming and the COVID-19 pandemic.J Behav Addict. 2020 Apr 29;9(2):184-6.

31. Ko C.H., Yen J.-Y. 2020. Impact of COVID-19 on gaming disorder: monitoring and prevention.J Behav Addict. 2020 Jun 6;9(2):187-9.

32. Mestre-Bach G, Blycker G, Potenza M. Pornography use in the setting of the COVID-19 pandemic.J Behav Addict. 2020 Jun;9(2):181-3.
33. Abrahao KP, Salinas AG, Lovinger DM. Alcohol and the Brain: Neuronal Molecular Targets, Synapses, and Circuits. Neuron.2017 Dec 20;96(6):1223-38.

34. Khantzian EJ. The self-medication hypothesis of substance use disorders: a reconsideration and recent applications. Harv Rev Psychiatry. 1997 JanFeb;4(5):231-44.

35. Zatoński WA, Wojtyła A. From the editors. J Health Inequal. 2019 Dec 30;5(2):121.

36. Chodkiewicz J, Talarowska M, Miniszewska J, Nawrocka N, Bilinski P. Alcohol Consumption Reported during the COVID-19 Pandemic: The Initial Stage. Int Environ Res Public Health. 2020 Jun 29;17(13):4677.

37. Rudenstine S, McNeal K, Schulder T, Ettman CK, Hernandez M, Gvozdieva K, et al. Depression and Anxiety During the COVID-19 Pandemic in an Urban, LowIncome Public University Sample. J Trauma Stress. 2020 Oct 12; 34(1):12-22.

\section{Acknowledgments}

We acknowledge the efforts of all members of the Federation of African Medical Students' Associations Standing Committee on Medical Education and Research, University of Ibadan Medical Students' Association Chapter (FAMSA-SCOMER, UIMSA Chapter) who helped in data collection for this study.

Conflict of Interest Statement a Funding

The Authors have no funding, financial relationships or conflicts of interest to disclose.

Author Contributions

Conceptualization, Investigation at Writing - Original Draft Preparation: AOB, DAO, HAS, AAA, CIU, BAB, YAA, AOA, LAO, DMB. Data Curation द Project Administration: AOB. Formal Analysis: AOB, YAA. Methodology: AAA, BAB. Writing - Review at Editing: AOB, DAO, HAS, AAA, CIU, BAB, YAA, AOA.

\section{Cite as}

Babatunde A0, Olawuyi DA, Shobanke HA, Adesola AA, Uche-Orji Cl, Bolatito BA, et al. Impact of CoVID-19 Lockdown on Depression Severity and the Use of Drugs Among University of Ibadan Students. Int J Med Students. 2021 Oct-Dec;9(4):264-8.

This work is licensed under a Creative Commons Attribution 4.0 International License

ISSN 2076-6327

This journal is published by the University Library System, University of Pittsburgh as part of the Digital Publishing Program and is co-sponsored by the University of Pittsburgh Press. 